\title{
Financialization in Kaleckian Economies with and without Labor Constraints
}

\author{
Soon Ryoo* and Peter Skott*
}

\begin{abstract}
Most Kaleckian models assume a perfectly elastic labor supply, an assumption that is questionable for many developed economies. This paper presents simple labor-constrained Kaleckian models and uses these models to compare the implications of financialization under labor-constrained and dual-economy conditions. The paper complements the analysis in Skott and Ryoo (2008) which did not include labor-constrained Kaleckian economies. We show that for plausible parameter values the financial changes commonly associated with financialization tend to be expansionary in both dual-economy and labor-constrained settings.
\end{abstract}

JEL classifications: EI2, E44

Keywords: financialization, stock-flow consistency, labor constraints, Kaleckian model

\section{Introduction}

Most Kaleckian models assume a perfectly elastic labor supply. This assumption - although reasonable in some contexts - is questionable for many developed countries with (near-) full employment and, as shown by Skott and Ryoo (2008), the implications of financialization (and the comparative statics of the models more generally) can depend critically on the la-

* University of Massachusetts, Amherst, USA.

Correspondence Address:

Soon Ryoo, Department of Economics, University of Massachusetts, Amherst, MA огоoz, USA; email: sryoo@econs.umass.edu

Received o8 February 2008, accepted I8 June 2008

(C) INTERVENTION 5 (2), 2008, 357-386 
bor market assumptions. Skott and Ryoo consider labor-constrained and dual-economy versions of Harrodian models. In the absence of a canonical labor-constrained Kaleckian model, however, they analyze only dual-economy versions of the Kaleckian model. This paper presents simple labor-constrained Kaleckian models and uses these models to compare the implications of financialization under labor-constrained and dual-economy conditions.

The basic approach is the same as in Skott and Ryoo. Financial stocks are included explicitly and the behavior of the household sector is characterized by desired stock-flow ratios. It is assumed that these ratios (which may depend on a range of variables, including rates of return) are attained in steady growth, and the analysis of the long-term effects of financial change can be broken down into two steps: the first step examines the effects of financial change, assuming that the desired stock-flow ratios are exogenous; a second step considers the effects of induced changes in the stock-flow ratios. The advantage of this approach, we suggest, is twofold. It focuses, first, on variables - stock-flow ratios - that are of obvious behavioral importance and by doing so guards against specifications that could otherwise lead to implausible trajectories for the stock variables. ${ }^{I}$ The comparative statics, second, are relatively simple and transparent when the stock-flow ratios are exogenous, and the qualitative results, it turns out, may carry over to the case with endogenously determined stock-flow ratios: most empirically plausible specifications yield small induced changes in the stock-flow ratios that do not overturn the qualitative results from the simple model with exogenous ratios.

The limitations of the present paper are also similar to those of Skott and Ryoo: the financial changes that we consider have been widely discussed but make up only a subset of the developments commonly associated with financialization; ${ }^{2}$ our focus is exclusively on the long run (steady-growth paths) with no attention to short-run dynamics; we look at a closed economy; there is no public sector and in our framework monetary policy simply determines the real rate of interest.

The rest of this paper is in five sections. Section 2 presents our dual-economy and labor-constrained versions of a Kaleckian model. Sections 3-4 analyze the effects of financial change in the two regimes. Section 5 considers the robustness of the results, and section 6 offers a few concluding remarks.

I Godley has called attention to this danger in a number of contributions; e.g. Godley and Cripps (1983). See Skott (198I, I988 and 1989) and Taylor (1985) for early introductions of explicit stock-flow relations in a post-Keynesian/structuralist context.

2 Krippner (2005), Epstein (2005) and Palley (2007), among others, discuss broader aspects of financialization. 


\section{Kaleckian Models}

\section{I Main Characteristics}

The structuralist/post Keynesian literature comprises different competing positions on a number of issues. Prominent areas of contention include the long-run sensitivity of the accumulation rate to changes in various arguments, including the utilization rate, and the influence of the state of the labor market on firms' pricing, output and investment decisions. Leaving aside whether Kalecki's own work fits this characterization, the standard Kaleckian models assume that: ${ }^{3}$

I. output (the utilization rate) adjusts instantaneously and costlessly to clear the product market.

2. the distribution of income is determined by firms pricing decisions with marginal cost taken as constant below full capacity. The markup on marginal cost need not be constant but is typically seen as structurally determined; Dutt (1984, section 5), for instance, allows the markup to depend on industry concentration. ${ }^{4}$

3. there is a low sensitivity of accumulation to variations in utilization, both in the short and the long run, and with a structurally determined markup, the utilization rate becomes an accommodating variable. Shocks to demand (changes in saving rates, for instance) can have large permanent effects on utilization, and the steady-growth value of the utilization rate is not, as in Harrodian or Robinsonian models, tied to a structurally determined desired rate. ${ }^{5}$

In addition to these characteristics, most Kaleckian models assume dual-economy conditions with a perfectly elastic supply of labor to the capitalist sector of the economy. Thus,

3 Influential formalizations of the Kaleckian model include Rowthorn (I98I), Dutt (1984), Taylor (1985) and Marglin and Bhaduri (1990). Lavoie and Godley (200I-2), Stockhammer (2005-6), Hein and van Treeck (2007), Dos Santos and Zezza (2007), Lavoie (2007) and van Treeck (2007) are among the recent contributions that have analysed financialization using a Kaleckian framework.

4 Not all contributions to the Kaleckian literature adhere strictly to this assumption. Marglin and Bhaduri (1990), for instance, introduce a pricing function that relates the markup to the rate of utilization but in a closely related paper, Bhaduri and Marglin (1990), suggest that the profit share be treated as exogenous. In models with overhead cost, full cost pricing is sometimes assumed (Lee [1985], Lavoie [1995]) and, as a variation on full cost pricing, Lavoie (1995a) and Hein and van Treeck (2007), respectively, have suggested an influence of interest rates and retention rates on the markup. We leave out overhead labor and take the markup - and hence the profit share - as exogenous.

5 Robinson (1962) assumes that adjustments in the markup generate a normal rate of utilization in steady growth; Steindl (1952) arguably held a similar position, see Flaschel and Skott (2006).

The difference compared to Harrodian models concerns the accumulation function; this issue has been debated by, among others, Auerbach and Skott (1988), Dutt (1997), Kurz (1986) and Lavoie (1995). It should be noted that a steady-growth path for the Kaleckian model may have utilization at a normak or sdesired level, despite the accommodating changes in utilization, if the desired utilization rate itself adjusts to the actual rate (Lavoie 1995, Dutt 1997); the plausibility of this mechanism, however, can be questioned (Skott 2008). 
the growth rate of the capitalist sector is determined with little or no reference to the labor market. Our Kaleckian models in this paper retain assumptions I-3 above. In our laborconstrained version, however, we modify the accumulation function by introducing the employment rate as an additional explanatory variable.

\subsection{Accumulation and Finance}

\subsection{Accumulation Under Dual-economy Conditions}

With a fixed coefficient production function, a general specification of the investment function in the dual-economy case includes the rate of capital utilization, the profit share, and financial variables like the real rate of interest, the valuation ratio (Tobin's q), and the ratios of debt and retained earnings to the value of the capital stock. Algebraically,

$$
g=\frac{I}{K}=f(u, \pi, r, q, m, c)
$$

where $g=I / K$ is the accumulation rate, $u=Y / K$ is a measure of utilization, $\pi$ the profit share, $r$ the real rate of interest, $q$ the valuation ratio, and $m$ and $c$ the ratios of debt and retained earnings to capital. ${ }^{6}$

Most, if not all, existing Kaleckian specifications are included as special cases of equation (I). This applies to the stagnationist specifications in Rowthorn (198I), Dutt (I984) and Taylor (1985) as well as the various cases considered by Marglin and Bhaduri (1990) and Taylor (199I). The financially oriented extensions in Lavoie and Godley (200I-2), Godley and Lavoie (2007), Dos Santos and Zezza (2007), Hein (2007) and van Treeck (2007) as well as the empirical specification in Ndikumana (1999) are also covered. To simplify the analysis in this paper we use a linearized version of $(\mathrm{I})$ :

$$
g=\gamma_{0}+\gamma_{1} u+\gamma_{2} \pi-\gamma_{3} r+\gamma_{4} q-\gamma_{5} m+\gamma_{6} c
$$

It should be noted that since many formulations in the literature involve some non-linearities (e.g. by letting accumulation depend on the rate of profit $\pi u$ or on the ratio of interest payments to capital $\mathrm{rm}$ ) the linear version (2) does not provide a global generalization of these specifications. Equation (2), however, can be viewed as a linear approximation to the nonlinear formulations, and locally it does cover the non-linear specifications as special cases.

\subsubsection{Accumulation in a Labor-constrained Economy}

There is no canonical labor-constrained Kaleckian model. Godley and Lavoie (2007) use government policy to bring the long-run growth rate into equality with the natural rate of growth. A very different approach is taken by Dutt (1992) who introduces distinct regimes and achieves the long-run consistency between actual and natural growth through alternating stages of unemployment and full-employment regimes, the unemployment regime

For simplicity we assume that there is no depreciation. 
being described by the standard model and the full-employment regime having output determined by a full employment constraint. Our approach is closer to Dutt than to GodleyLavoie in that we leave out the public sector and examine the adjustment of a pure capitalist economy to changes in employment. Dutt, however, does not include financial stocks and, unlike Dutt, we do not introduce a distinct full employment regime but instead modify the accumulation function.

The influence of employment rates on growth and distribution have been the centerpiece in a number of models, including Goodwin (1967) and Skott (1989a).7 Both of these papers deviate substantially from the standard Kaleckian framework in the way they endogenize movements in the profit share: Goodwin allows income distribution (the markup) to be influenced directly by the size of the reserve army while Skott introduces slow output adjustment and assumes that prices (and the distribution of income) respond to demand conditions in the product market. In this paper we stay closer to the standard Kaleckian model: we assume costless and instantaneous output adjustment and take the markup (the profit share) as an exogenous variable.

The simplest way of introducing a role for the employment rate in this Kaleckian setting is to allow for a direct influence of employment on the rate of accumulation. Two related but distinct mechanisms may bring about this result. A high employment rate (a small reserve army of labor) strengthens workers. As workers step up demands for wage increases and improvements in non-wage features of the employment relation, and as their willingness to back up these demands with industrial action increases, the business climate suffers and animal spirits drop. A state of near-full employment, second, is likely to affect firms' views on their ability to get the workers they would need to increase future output, and a downward adjustment in the expected growth rate of output will reduce the need for additions to the capital stock. ${ }^{8}$ The appearance of labor shortages may also generate policy responses in the form of increasing interest rates and/or contractionary fiscal policy. This third mechanism is excluded from our model of a pure capitalist economy which deliberately leaves out a public sector and policy intervention of this kind.

Introducing a negative effect of employment on accumulation - but retaining a simple linear specification - the accumulation function can be written as

$$
g=\gamma_{0}+\gamma_{1} u+\gamma_{2} \pi-\gamma_{3} r+\gamma_{4} q-\gamma_{4} m+\gamma_{6} c-\gamma_{7} e
$$

The employment rate $e$, in turn, is given by

$$
e=\frac{L}{Y} \frac{Y}{K} \frac{K}{\bar{L}}=\mu u k
$$

7 Other contributions include Dutt (2006), Stockhammer (2004a) and Palley (1996).

8 Arguing along similar lines, Robinson (1962: 55) suggests that when the scarcity of labour sets in, firms may "refrain from building plants that they will be unable to man. The desired rate of accumulation is then tailored to fit the possible rate." 
where $\mu=L / K$ is the technically given labor-output ratio and $k=K / \bar{L}$ is the ratio of the capital stock to the total labor force.

The linearity assumption may be particularly unreasonable with respect to the employment rate. Small variations in the employment rate will not matter for accumulation if unemployment is high but are likely to have a significant influence on accumulation if the economy is close to full employment. To accommodate this non-linearity, the linear term $\gamma_{7} e$ could be replaced by an increasing, convex function $f(e)$. This alternative specification could provide a unified treatment of the labor-constrained and dual-economy cases: simply let $f^{\prime}(e)=0$ for $0<e \leq \bar{e}<1$ and $f^{\prime}>0$ for $e>\bar{e}$. The dual economy then corresponds to employment rates below $\bar{e}$.

We use the linear approximation in the main text but briefly consider the implications of a non-linear formulation in Appendix B.

Another re-specification of the accumulation function is outlined in section 5.2. This alternative formulation uses equation (2) but introduces dynamic adjustments in the constant $\gamma_{0}$. Unlike equation (2a), this specification implies a unique steady-growth solution for employment.

\subsubsection{Finance Constraints}

Investment has to be financed and we consider three sources of finance: retained earnings, new equity issues and debt finance (bank loans). Thus, the aggregate finance constraint for the firm sector can be written:

$$
p I+i M=\Pi-D i v+v \dot{N}+\dot{M}
$$

where $I, \Pi$, Div, $M$ and $N$ denote aggregate investment and aggregate profit, net dividend payments from firms to other sectors, net debt to other sectors, and the aggregate number of shares held by other sectors; $i$ is the nominal interest rate on bank loans, and $p$ and $v$ are the price of output (= the price of investment goods) and the price of equity, respectively; a dot over a variable is used to denote a time derivative, $\dot{z}=d z / d t$.

We assume that dividends are given by

$$
\text { Div }=\left(1-s_{f}\right)(\Pi-r M)
$$

where $r$ is the real rate of interest, $r=i-\hat{p}$, and $s_{f}$ is the retention rate out of profits net of interest payments. This specification of dividends is used also by, among others, Lavoie and Godley (200I-2) and Dos Santos and Zezza (2007).

Using equation (3), the finance constraint can be rewritten

$$
p I=s_{f}(\Pi-r M)+v N \hat{N}+M(\hat{M}-\hat{p})
$$

where a hat over a variable denotes the growth rate of the variable $(\hat{z}=\dot{z} / z=(d z / d t) / z)$. The finance constraint shows that, given the levels of investment and profits and the inherited debt, firms cannot choose the retention rate, the rate of new issues and the amount of new debt independently. One of these three variables will have to accommodate so as to ensure 
that the finance constraint is being met. In reality, of course, there may be dynamic feedback effects: an unexpected need for external finance in one period, for instance, may influence firms' retention rates and/or new issue policies in subsequent periods.

In this paper we describe firms' financial behavior in terms of their retention rate $\left(s_{f}\right)$ and the share of investment that is being financed by new issues $(x) .{ }^{9}$ Thus, we treat debt finance as the accommodating variable and assume that the rate of new issues is determined by

$$
\widehat{N}=\frac{x p I}{v N}
$$

\subsection{Banks}

Banks give loans to firms and accept deposits from households. Neither firms nor households hold cash. When banks provide a loan to a firm, the money therefore returns to the bank immediately, either as deposits from households or because other firms use their increased revenues to reduce their debt. The loan and deposit rates are equal and there are no costs involved in banking. Thus, banks make neither profits nor losses, ${ }^{10}$ and the firm sector has a net debt $(M)$ that must equal the total deposits of the household sector (=money demand, $M^{H}$ ):

$$
M=M^{H}
$$

Banks determine the nominal interest rate. This nominal rate, however, will typically depend on inflation and the real rate of interest will be constant in steady growth. To simplify the exposition, we treat the real rate of interest $r(=i-\hat{p})$ as an exogenous variable set by the banking system.

\subsection{Households}

In analogy with firms, households face a budget (or finance) constraint. For the household sector as a whole it takes the form

$$
p C+v \dot{N}^{H}+\dot{M}^{H}=W+D i v^{H}+i M^{H}
$$

where $C$ is consumption, $W$ wage income, $N^{H}, M^{H}$ indicate household holdings of shares and deposits (money), and $D i v^{H}$ is dividend payments received by the household sector.

9 One could also, following Eichner (1976) and Wood (1975), assume that firms set the shares of investment that are to be financed by the three different sources, with both $s_{f}$ and $\widehat{N}$ varying in response to changes in accumulation. This case is considered in Skott (1989: ch. 7); it is also the approach used in Godley and Lavoie (2007). Another alternative, used by Skott (1989: chs. 4-5) is to treat $\widehat{N}$ as the exogenous variable that describes firm behavior.

IO The share valuation of banks therefore is zero, and this simple version of the model does not capture changes in the shares of the financial sector in GDP and financial-sector profits in total profits. 
The steady-growth implications of household consumption and saving behavior can be described in terms of stock-flow ratios of assets to income. Specifically, let

$$
\begin{aligned}
& M^{H}=\beta\left(i, r, r^{e}, \pi, \ldots\right) p Y \\
& v N^{H}=\alpha\left(i, r, r^{e}, \pi, \ldots\right) p Y
\end{aligned}
$$

where the stock-flow ratios $\alpha$ and $\beta$ may depend on a number of variables, including the real rates of return on deposits $(r)$ and equity $\left(r^{e}\right)$. Theories differ with respect to the determination of the (steady-growth) values of these stock-flow ratios, and we examine different specifications, including cases where only rentiers save, as in van Treeck (2007).

The stock-flow ratios and the finance constraint together determine consumption. Using the budget constraint (6), the dividend equation (3), the new equity condition (5), the equilibrium conditions $M=M^{H}$ and $N=N^{H}$, and the stock-flow relations (7)-(8), we have:

$$
\begin{aligned}
\frac{C}{K} & =u\left[1-s_{f}(\pi-r \beta)+\beta(\hat{p}-\hat{M})-\alpha \hat{N}\right] \\
& =u\left[1-s_{f}(\pi-r \beta)-\beta g\right]-x g
\end{aligned}
$$

where the last equation in (9) makes use of the steady-growth condition $\widehat{M}=\widehat{\beta}+\widehat{p}+\hat{Y}=$ $\hat{p}+g$.

It should be noted that when theories are cast in terms of flow-flow relations (e.g. consumption as a function of distributed incomes and capital gains, as in Lavoie-Godley [200I-2]), the steady-growth implications of the flow-flow relations can be described by stock-flow equations like (6)-(8). These stock-flow implications, moreover, may provide a clearer picture of the mechanisms behind the steady-growth effects of changes in financial behavior than the original flow-flow specifications.

\section{Financial Change: The Dual-economy Case ${ }^{I I}$}

\section{I Exogenous Stock-flow Ratios}

By using the definition of $\alpha$ and $\beta$, Tobin's q, the debt-capital ratio, and the ratio of retained earnings to capital can be written as:

$$
\begin{aligned}
& q=\frac{M+v N}{p K}=(\alpha+\beta) u \\
& m=\frac{M}{p K}=\beta u \\
& c=\frac{s_{f}(\Pi-r M)}{p K}=s_{f}(\pi-r \beta) u
\end{aligned}
$$

II Skott and Ryoo (2008: sections 5.I- 5.2) analyze Kaleckian dual economies but, unlike the present paper, focus mainly on the specification of accumulation and consumption in Lavoie and Godley (200I-2). 
and the accumulation function (2) can be rewritten:

$$
\begin{aligned}
g & =\gamma_{0}+\left(\gamma_{2} \pi-\gamma_{3} r\right)+\left[\gamma_{1}+(\alpha+\beta) \gamma_{4}-\gamma_{5} \beta+\gamma_{6} s_{f}(\pi-r \beta)\right] u \\
& =\gamma_{0}+\delta_{0}+\delta u
\end{aligned}
$$

where $\delta_{0} \equiv \gamma_{2} \pi-\gamma_{3} r$ and $\delta \equiv \gamma_{1}+(\alpha+\beta) \gamma_{4}-\gamma_{5} \beta+\gamma_{6} s_{f}(\pi-r \beta)$. For empirically reasonable magnitudes of the negative effect on capital accumulation of the debt-capital ratio, accumulation is increasing in the utilization rate, i.e. $\delta>0$, but following the Kaleckian tradition, we assume that saving is more responsive than investment to changes in the utilization rate. This stability condition implies - using (9) and (го) - that if the $\alpha$ - and $\beta$-ratios are exogenous, then

$$
s_{f}(\pi-r \beta)+\beta(\delta u+g)-(1-x) \delta>0
$$

The equilibrium condition for the product market is given by

$$
(1-x-\beta u)\left(\gamma_{0}+\delta_{0}+\delta u\right)=s_{f}(\pi-r \beta) u
$$

and - assuming positive autonomous investment, $\gamma_{0}+\delta_{0}>0$ - there is a unique positive equilibrium solution for $u .^{\text {I2 }}$

The comparative statics for the utilization rate are given by:

$$
\begin{aligned}
\frac{\partial u}{\partial \pi} & =-\frac{s_{f} u-(1-x-\beta u)\left(s_{f} \gamma_{6} u+\gamma_{2}\right)}{s_{f}(\pi-r \beta)+\beta(\delta u+g)-(1-x) \delta} \\
\frac{\partial u}{\partial s_{f}} & =-\frac{(\pi-r \beta)\left[1-(1-x-\beta u) \gamma_{6}\right] u}{s_{f}(\pi-r \beta)+\beta(\delta u+g)-(1-x) \delta}<0 \\
\frac{\partial u}{\partial x} & =-\frac{g}{s_{f}(\pi-r \beta)+\beta(\delta u+g)-(1-x) \delta}<0 \\
\frac{\partial u}{\partial r} & =\frac{s_{f} \beta u-(1-x-\beta u)\left(\gamma_{3}+\gamma_{6} s_{f} \beta u\right)}{s_{f}(\pi-r \beta)+\beta(\delta u+g)-(1-x) \delta} \\
\frac{d u}{d \alpha} & =\frac{(1-x-\beta u) \gamma_{4} u}{s_{f}(\pi-r \beta)+\beta(\delta u+g)-(1-x) \delta}>0 \\
\frac{d u}{d \beta} & =\frac{\left[\left(s_{f} r-g\right)+(1-x-\beta u)\left(\gamma_{4}-\gamma_{5}-\gamma_{6} s_{f} r\right)\right] u}{s_{f}(\pi-r \beta)+\beta(\delta u+g)-(1-x) \delta}
\end{aligned}
$$

Depending on parameter values, the model, not surprisingly, may generate either stagnationist and exhilarationist outcomes (in the sense of Marglin and Bhaduri [1990]), the stag-

I2 If the stability condition (II) holds for all values of $u$ then there can be at most one equilibrium solution. A positive solution exists if and only if autonomous investment is positive. To see this, note that the equilibrium condition can be written

$$
(1-x)\left(\gamma_{0}+\delta_{0}\right)-A u-\beta \delta u^{2}=0
$$

where $A$ is positive if the stability condition holds for $u=0$. 
nationist case with $\partial u / \partial \pi<0$ in equation (I2) arising if saving responds more strongly than investment to changes in the profit share $\left(s_{f} u+(x+\beta u)\left(s_{f} \gamma_{6} u+\gamma_{2}\right)>\left(s_{f} \gamma_{6} u+\gamma_{2}\right)\right)$.

For present purposes changes in the financial variables may be more interesting, and financialization has been associated with a decline in both the retention rate and new issues. Strikingly, as long as $g>0$ and $(1-x-\beta u) \gamma_{6}<1$, the effects on utilization of reductions in the retention rate $\left(s_{f}\right)$ or the share of equity finance $(x)$ are unambiguously positive. The growth condition $(g>0)$ is invariably assumed to hold in Kaleckian models, and it is difficult to see how an increase in retained earnings - keeping constant $u, \pi, r, q, m$ - can lead to more than a one-for-one increase in investment, that is, one would expect $\gamma_{6}$ to be well below one, and the second condition for expansionary effects will also be met.

An increase in $\alpha$ - another aspect of financialization - also has an unambiguously positive effect on utilization; an increase in $\alpha$ does not affect the saving rate but merely leads to an increase in equity prices and a decline in the rate of new issues $(\hat{N})$ as firms maintain an unchanged ratio of equity finance. ${ }^{\mathrm{I3}}$

Unlike $s_{f}, x$ and $\alpha$, the effects of changes in $r$ and $\beta$ are ambiguous. An increase in the real interest rate has a negative impact on both saving and investment. It lowers the amount of corporate saving, and the decrease in retained earnings depresses accumulation for a given rate of utilization. Saving falls more sharply than investment if the direct negative impact on investment of changes in $r$ is not too large, i.e. if $s_{f} \beta u>(1-\mathrm{x}-\beta u)\left(\gamma_{3}+\gamma_{6} s_{f} \beta u\right)$. Under this assumption, to restore the product market equilibrium, a higher utilization rate is required. With a reversal of this inequality, a higher real interest rate requires a lower utilization rate for the product market equilibrium. The ambiguity of the effect of changes in $r$ may not matter for an evaluation of the effects of financialization. It is sometimes suggested that financialization has generated a rise in interest rates, but interest rates have declined since the early I980s and currently are not above historical averages.

Turning to the growth rate, the effects on accumulation of changes in the financial variables are given by:

$$
\begin{aligned}
& \frac{\partial g}{\partial \pi}=\gamma_{2}+\gamma_{6} s_{f} u+\delta \frac{\partial u}{\partial \pi} \\
& \frac{\partial g}{\partial s_{f}}=\gamma_{6}(\pi-r \beta) u+\delta \frac{\partial u}{\partial s_{f}} \\
& \frac{\partial g}{\partial x}=\delta \frac{\partial u}{\partial x}<0 \\
& \frac{\partial g}{\partial r}=-\gamma_{3}-\gamma_{6} s_{f} \beta u+\delta \frac{\partial u}{\partial r} \\
& \frac{\partial g}{\partial \alpha}=\gamma_{4} u+\delta \frac{\partial u}{\partial \alpha}>0
\end{aligned}
$$

I3 The expression $1-x-\beta u=s_{f}(\Pi-r M) / p I$ is positive as long as profits exceed real interest payments on debt; a steady growth path that violated this condition would not be viable. 


$$
\frac{\partial g}{\partial \beta}=\left(\gamma_{4}-\gamma_{5}-\gamma_{6} s_{f} r\right) u+\delta \frac{\partial u}{\partial \beta}
$$

The result for $\partial g / \partial \pi$ in equation (I8) is parallel to Marglin and Bhaduri's (1990) analysis of wage and profit led growth. The direct and positive effect on accumulation of an increase in the profit share may or may not be dominated by the effect of a decline in utilization. A rise in the retention rate - equation (19) - also produces conflicting effects on accumulation. The first term in (19), $\gamma_{6}(\bar{\pi}-r \beta) u$, captures a direct positive impact on accumulation from an increase in the amount of internal funds, but an increase in the retention rate also has a negative effect on accumulation by lowering the utilization rate (the second term in [I9], $\delta\left(\partial u / \partial s_{f}\right)$, is negative). Which effect dominates is an empirical matter. It is readily seen, however, that increases in the retention rate must reduce growth if the economy is wage led: using the expressions for $\partial u / \partial \pi$ and $\partial u / \partial s_{f}$ it follows that $\partial g / \partial s_{f}>0$ is a sufficient condition for growth to be profit led..$^{14}$

The effects on capital accumulation of a decrease in equity finance or an increase in households' desired ratio of equity to income are more clear-cut. A decrease in $x$ leads to a higher rate of utilization, and the higher utilization rate raises capital accumulation; an increase in $\alpha$ has a direct positive impact on capital accumulation through the Tobin's q-channel, and this direct impact is strengthened by a positive utilization effect.

Changes in the real interest rate have ambiguous effects. The direct effect on accumulation of a rise in the real rate of interest is negative but the derived effect on accumulation via changes in the utilization may be positive: the term $-\gamma_{3}-\gamma_{6} s_{f} \beta u$ in (2I) is negative, but the sign of $\delta(\partial u / \partial r)$ can be positive or negative, leaving unclear the sign of the total effect. The ambiguity that characterizes the effects of changes in $\beta$ on utilization also carries over to the effects on the growth rate.

If we focus on the three main changes associated with financialization - an increase in the value of equity holdings and a decline in both equity finance and the retention rate - the only ambiguity concerns the growth effect of a decline in the retention rate. This ambiguity disappears if we set $\gamma_{6}$ equal to zero, as do most existing specifications in the post-Key-

I4 We have

$$
\begin{aligned}
\frac{\partial g}{\partial \pi} & =\gamma_{2}+\gamma_{6} s_{f} u+\delta \frac{\partial u}{\partial \pi} \\
& =\gamma_{2}+\gamma_{6} s_{f} u+\delta \frac{(1-x-\beta u) \gamma_{2}-u s_{f}\left\{1-(1-x-\beta u) \gamma_{6}\right\}}{s_{f}(\pi-r \beta)+\beta(\delta u+g)-(1-x) \delta} \\
& =\gamma_{2}+\delta \frac{(1-x-\beta u) \gamma_{2}}{s_{f}(\pi-r \beta)+\beta(\delta u+g)-(1-x) \delta} \\
& +\frac{s_{f}}{\pi-r \beta}\left[\gamma_{6}(\pi-r \beta) u-\delta \frac{(\pi-r \beta)\left[1-(1-x-\beta u) \gamma_{6}\right] u}{s_{f}(\pi-r \beta)+\beta(\delta u+g)-(1-x) \delta}\right] \\
& =\gamma_{2}+\delta \frac{(1-x-\beta u) \gamma_{2}}{s_{f}(\pi-r \beta)+\beta(\delta u+g)-(1-x) \delta}+\frac{s_{f}}{\pi-r \beta} \frac{\partial g}{\partial s_{f}}
\end{aligned}
$$


nesian/structuralist literature, including Dutt (1984), Taylor (1985), Marglin and Bhaduri (1990), Godley and Lavoie (2007) and Lavoie (2007). With $\gamma_{6}=0$, the three key changes associated with financialization are unambiguously expansionary in this Kaleckian dualeconomy model with exogenous stock-flow ratios.

\subsection{The Godley-Lavoie Specification of Consumption and Accumulation}

The constancy assumption for the stock-flow ratios is violated by most specifications of consumption behavior. Rather than being constant, the $\alpha$ and $\beta$ ratios become endogenous and the response of investment to changes in $\mathrm{u}$ will be affected by these endogenous adjustments of the stock-flow ratios. An example is the recent specification of consumption by Godley and Lavoie (2007). Unlike the earlier specification in Lavoie-Godley (200I-2) this more recent specification is quite conventional and similar (or identical) specifications have been used by, among others, Ando and Modigliani (1963) and Dos Santos and Zezza (2007).

The full Godley-Lavoie model is quite complex. The government sector plays a central role in the model, unfulfilled short-run expectations generate movements in inventories, and the model includes multiple financial assets. ${ }^{15}$ Our stripped-down model in this section leaves out most of these elements but uses the Godley-Lavoie specifications of consumption, portfolio behaviour and investment. Thus, we assume that consumption is given by

$$
\frac{C}{K}=c_{1} y+c_{2} q
$$

and that households' portfolio choice can be described by

$$
\beta /(\alpha+\beta)=\left(1-\gamma_{0}\right)+\gamma_{1}(r+\hat{p})-\gamma_{2} r^{e}+\gamma_{3} y / q
$$

where $y=\left[1-s_{f}(\pi-r \beta)+\hat{p} \beta\right] u, r^{e}=\frac{\left(1-s_{f}\right)(\pi-\beta r) u+g(\alpha u-x)}{\alpha u}$ and $q=(\alpha+\beta) u$. This consumption behavior is combined with a simple accumulation function given by

$$
g=\gamma_{0}+\gamma_{1} u-\gamma_{3} r
$$

where $\gamma_{0}, \gamma_{1}$, and $\gamma_{3}$ are positive constants. This specification is clearly a special case of equation (2) with $\gamma_{2}=\gamma_{4}=\gamma_{5}=\gamma_{6}=0$.

The steady-growth relation between consumption and stock-flow ratios is given by (9), reproduced here for convenience,

$$
\frac{C}{K}=u\left[1-s_{f}(\pi-r \beta)-\beta g\right]-x g
$$

The condition for the product market equilibrium closes the model,

$$
u=\frac{C}{K}+g
$$

I5 They also endogenize the profit share by assuming that (in steady growth) it is increasing in $I / Y$ and $m$. Given the absence of a generally accepted theory of markup determination, we prefer to keep the profit share as an exogenous variable. 
Given the definition of $y, q$ and $r^{e}$, five equations (24)-(27) and (9) determine the steadystate values of five endogenous variables: $C / K, u, g, \alpha$ and $\beta$.

Our particular interest lies in how endogenous changes in stock-flow ratios, $\alpha$ and $\beta$ affect our results in 3.I, and two cases can be distinguished. In the first case, the relaxation of the constancy assumption of $\alpha$ and $\beta$ does not change the signs of the comparative statics in (12)-(23). In the second case, the endogenous changes in $\alpha$ and $\beta$ reverse all or some of the signs of those partial derivatives. In the terminology of Skott and Ryoo (2008), the former case is stock-flow inelastic and the latter stock-flow elastic.

It is not impossible to get analytical results for the comparative statics associated with (24)-(27) and (9). The complexity of the expressions for the partial derivatives, however, make the analytical results rather uninformative and numerical evaluation is needed to get a clearer picture.

Table I: Kaleckian Dual-economy

\begin{tabular}{lrcrc}
\hline \multicolumn{1}{c}{ Regimes } & \multicolumn{2}{c}{ Utilization } & \multicolumn{2}{c}{ Accumulation } \\
& Exogenous & Endogenous & Exogenous & Endogenous \\
& $\alpha$ and $\boldsymbol{\beta}$ & $\alpha$ and $\boldsymbol{\beta}$ & $\alpha$ and $\boldsymbol{\beta}$ & $\boldsymbol{\alpha}$ and $\boldsymbol{\beta}$ \\
\hline The retention rate & -0.634 & -0.628 & -0.032 & -0.031 \\
\hline Equity issues & -0.564 & -0.542 & -0.028 & -0.027 \\
Real interest rate & 1.301 & 1.272 & -0.035 & -0.036 \\
Profit share & -1.578 & -1.566 & -0.079 & -0.078 \\
Propensity to hold equity & - & 0.033 & - & 0.002 \\
\hline
\end{tabular}

Notes: The results are based on the system of (9) and (24)-(27) in section 3.2. For the procedure used to construct this table, see Appendix A.

a. Numbers in the table show the partial derivatives of the utilization rate and the growth rate with respect to the parameters listed in the first column.

b. Parameter values: $\left(\gamma_{0}, \gamma_{1}, \gamma_{3}\right)=(0.0088,0.05,0.1),\left(s_{f}, \pi, x\right)=(0.75,0.33,0.05),\left(c_{1}, c_{2}\right)=(0.75$, $0.064),\left(\lambda_{0}, \lambda_{1}, \lambda_{2}, \lambda_{3}\right)=(0.6,0.2,0.013,0.0001),(i, \hat{p}, d)=(0.03,0,0.1)$.

Table I compares the effects of parameter changes using the Godley-Lavoie consumption and portfolio specification - endogenous $\alpha$ and $\beta$ case - to those in the exogenous $\alpha$ and $\beta$ case. The table shows the partial derivatives of the utilization rate and the growth rate with respect to the parameters listed in the first column, evaluated at the steady-state values. ${ }^{16}$ The results are clear. The comparative statics regarding the effects of financial changes on utilization and growth are almost identical for those two cases in terms of both signs and

I6 Appendix A explains the procedure used to construct Table I. We use the same parameter values for $\gamma_{1}, \gamma_{2}, c_{1}$ and $c_{2}$ as Godley and Lavoie (2007); the values of all other parameters are in line with those conventionally accepted in stock-flow consistent modeling exercises. 
magnitudes. Putting it differently, the effects of induced changes in $\alpha$ and $\beta$ on $u$ and $g$ are negligible, and the system is stock-flow inelastic.

Table 2: Effects of Changes in Financial Variables on Stock-flow Ratios in Kaleckian Dual-economy

\begin{tabular}{c|ccc|ccc|ccc}
\hline & \multicolumn{3}{|c|}{$\boldsymbol{s}_{\boldsymbol{f}}$} & \multicolumn{3}{c|}{$\boldsymbol{x}$} & \multicolumn{3}{c}{$\boldsymbol{r}$} \\
& $\mathbf{0 . 5 5}$ & $\mathbf{0 . 7 5}$ & $\mathbf{0 . 9 5}$ & $-\mathbf{0 . 0 5}$ & $\mathbf{0 . 0 5}$ & $\mathbf{0 . 1 5}$ & $\mathbf{0 . 0 1}$ & $\mathbf{0 . 0 3}$ & $\mathbf{0 . 0 5}$ \\
\hline $\boldsymbol{\alpha}$ & 1.486 & 1.407 & 1.296 & 1.590 & 1.407 & 1.175 & 1.378 & 1.407 & 1.436 \\
$\boldsymbol{\beta}$ & 1.009 & 0.958 & 0.885 & 1.082 & 0.958 & 0.800 & 0.922 & 0.958 & 0.994 \\
\hline
\end{tabular}

Notes: $0.75\left(s_{f}\right), 0.05(x), 0.03(r)$ are the baseline values. For other baseline parameter values, see notes in Table I.

Table 3: Sensitivity Analysis in Kaleckian Dual Economy

\begin{tabular}{|c|c|c|c|c|c|c|c|}
\hline$c_{2}$ & $c_{1}$ & 0.5 & 0.6 & 0.7 & 0.8 & 0.9 & 0.95 \\
\hline 0.01 & & * & * & * & * & o & o \\
\hline 0.03 & & $*$ & * & $*$ & o & o & o \\
\hline 0.05 & & * & * & o & o & o & • \\
\hline 0.07 & & * & * & o & o & o & • \\
\hline 0.09 & & * & o & o & o & o & • \\
\hline 0.10 & & o & o & o & o & 0 & • \\
\hline
\end{tabular}

Notes: The table above shows that the system of (9) and (24)-(27) in section 3.2 satisfies our stockflow inelasticity conditions for all combinations of the values of $c_{1}$ and $c_{2}$ listed in the table with a minor exception marked by $\bullet<$ in which only the sign of $u_{r}$ is reversed (For other parameter values, see notes in Table I).

a. Cases marked by $*:: u_{s f}<0, u_{x}<0, u_{r}>0, g_{s f}<0, g_{x}<0$, and $g_{r}>0$.

b. Cases marked by ro: $u_{s f}<0, u_{x}<0, u_{r}>0, g_{s f}<0, g_{x}<0$, and $g_{r}<0$.

c. Cases marked by $\bullet \bullet: u_{s f}<0, u_{x}<0, u_{r}<0, g_{s f}<0, g_{x}<0$, and $g_{r}<0$.

d. Cases marked by $\bullet<:$ The results are the same as the cases marked by ro except that $u_{r}>0$ in the case with exogenous $\alpha$ and $\beta$ but $u_{r}<0$ in the case with endogenous $\alpha$ and $\beta$.

Table 2 provides a clue to understanding these results. It illustrates the sensitivity of $\alpha$ and $\beta$ to variations in $s_{f}, x$ and $r$. It is readily seen that the variations of the financial stock-flow ratios in response to changes in $s_{f} x$ and $r$ are very small, even when the magnitudes of changes in parameter values themselves are substantial. Table 3 shows that the qualitative results in Table I are robust for a range of values for the consumption function parameters $\left(c_{1}\right.$ and $\left.c_{2}\right)$. The partial derivatives of $u$ and $g$ with respect to $s_{f}, x$ and $r$ are preserved in all cases marked

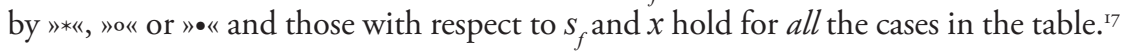

I7 The effects of changes in $r$ depend on the values of the consumption parameters $\left(c_{1}, c_{2}\right)$ not only 
To conclude, a Godley-Lavoie specification clearly has endogenous stock-flow ratios, but for plausible parameter values these stock-flow ratios are inelastic in the sense of Skott and Ryoo (2008): induced changes in $\alpha$ and $\beta$ do not reverse the signs of the key partial derivatives that were obtained with exogenous ratios.

\section{Financial Change: The Labor-constrained Case}

\section{I Exogenous Stock-flow Ratios}

In a labor-constrained regime the growth rate of the economy must be equal to the snatural rates, $n$. The natural rate may embody technical change as well as an increasing labor force, and the natural rate of growth need not be exogenous. It would seem quite reasonable, for instance, to assume that the natural rate depends positively on the employment rate: labor shortages may speed up the search for new labor-saving technologies and also draw in extra workers through immigration, say, or changes in participation rates and retirement patterns. ${ }^{18}$ To simplify the exposition, however, we treat $n$ as an exogenous constant in the main text but briefly consider an endogenous natural rate in Appendix B.

Using the consumption function (9) and the steady-growth requirement $\widehat{K}=n$, the utilization rate must be given by:

$$
u=\frac{(1-x) n}{s_{f}(\pi-r \beta)+\beta n}
$$

Using this expression for $u$, we get the following comparative statics:

$$
\begin{aligned}
\frac{\partial u}{\partial \pi} & =-\frac{s_{f}(1-x) n}{\left[s_{f}(\pi-r \beta)+\beta n\right]^{2}}<0 \\
\frac{\partial u}{\partial s_{f}} & =-\frac{(\pi-r \beta)(1-x) n}{\left[s_{f}(\pi-r \beta)+\beta n\right]^{2}}<0 \\
\frac{\partial u}{\partial x} & =-\frac{n}{s_{f}(\pi-r \beta)+\beta n}<0 \\
\frac{\partial u}{\partial r} & =\frac{s_{f} \beta(1-x) n}{\left[s_{f}(\pi-r \beta)+\beta n\right]^{2}}>0 \\
\frac{\partial u}{\partial \alpha} & =0
\end{aligned}
$$

in the case with endogenous $\alpha$ and $\beta$ but also in the exogenous case. The reason is simple: the effects of changes in $r$ depend on the value of the stock-flow ratios and the comparison between the endogenous and exogenous cases has to be made with the same initial stock-flow ratios (see Appendix I).

I8 Changes in participation rates and retirement patterns clearly cannot affect the growth rate in the svery long run but the effects may be felt over time scales that are consistent with a long-run analysis. 


$$
\frac{\partial u}{\partial \beta}=-\frac{\left(n-s_{f} r\right)(1-x) n}{\left[s_{f}(\pi-r \beta)+\beta n\right]^{2}}
$$

These results for the effects on utilization are independent of the accumulation function. The accumulation function, however, is important for the determination of the steady-growth value of the employment rate (and for the stability properties of the system).

Using the accumulation function (2a) and the solution for $u$ in (28), we get the steadygrowth employment rate,

$$
e=\frac{\gamma_{0}+\delta_{0}-n+\delta u}{\gamma_{7}}
$$

where $\delta_{0} \equiv \gamma_{2} \pi-\gamma_{3} r$ and $\delta \equiv \gamma_{1}+(\alpha+\beta) \gamma_{4}-\gamma_{5} \beta+\gamma_{6} s_{f}(\pi-r \beta)$. The employment effects of changes in the parameters are readily obtained:

$$
\begin{aligned}
\frac{\partial e}{\partial \pi} & =\frac{1}{\gamma_{7}}\left[\gamma_{2}+\gamma_{6} s_{f} u+\delta \frac{\partial u}{\partial \pi}\right] \\
\frac{\partial e}{\partial s_{f}} & =\frac{1}{\gamma_{7}}\left[\gamma_{6}(\pi-r \beta) u+\delta \frac{\partial u}{\partial s_{f}}\right] \\
\frac{\partial e}{\partial x} & =\frac{1}{\gamma_{7}}\left[\delta \frac{\partial u}{\partial x}\right]<0 \\
\frac{\partial e}{\partial r} & =\frac{1}{\gamma_{7}}\left[-\gamma_{3}-\gamma_{6} s_{f} \beta u+\delta \frac{\partial u}{\partial r}\right] \\
\frac{\partial e}{\partial \alpha} & =\frac{1}{\gamma_{7}}\left[\gamma_{4} u\right]>0 \\
\frac{\partial e}{\partial \beta} & =\frac{1}{\gamma_{7}}\left[\left(\gamma_{4}-\gamma_{5}-\gamma_{6} s_{f} r\right) u+\delta \frac{\partial u}{\partial \beta}\right]
\end{aligned}
$$

The results in (35) - (40) have a simple intuitive interpretation. Changes in $e$ are used, essentially, to keep the accumulation rate equal to the natural rate $n$. Thus, an increase in employment is needed if otherwise the growth rate were to rise above $n$, and a decrease is needed if an unchanged value of $e$ would lead to a decline in the growth rate. The changes in growth - for fixed $e$ - have been derived already in equations (18)-(23), and the effects on employment are obtained simply by multiplying these expressions by the factor $1 / \gamma_{7}$.

Before closing this section, it should be noted that the comparative results have been derived assuming the existence of a steady state path with $\widehat{K}=\hat{Y}=n$ and $0 \leq e \leq 1$. This premise need not hold: low sanimal spirits and/or a high natural rate of growth may imply that the growth of a capitalist economy falls short of the natural rate. In this case, the value of $k$ and the employment rate both converge to zero, and the comparative statics regarding financial changes follows those given in section 3.I. 


\subsection{The Godley-Lavoie Specification of Consumption and Accumulation}

In this section, we relax the assumption of the constancy of $\alpha$ and $\beta$, as in section 3.2, but the labor constraint is assumed to be binding. Thus, $g=n$ and the investment function (26) is replaced by (4I) below:

$$
g=\gamma_{0}+\gamma_{1} u-\gamma_{3} r-\gamma_{7} e
$$

After substituting $\mathrm{n}$ for $\mathrm{g}$, five equations (24), (25), (9), (27) and (4I) determine five endogenous variables, $u, e, C / K, \alpha$ and $\beta$. We are interested in whether the qualitative results from section 4.I carry over to the current case with endogenous adjustment of the stock-flow ratios. As in section 3.2, analytical expressions are complicated and uninformative and we resort to numerical simulation.

The parameter values are the same as those in section 3.2, the only difference being that with the additional term $\gamma_{7} e$, it becomes reasonable to adjust the constant $\gamma_{0}$ in the accumulation function. To make the benchmark results as comparable as possible to those in 3.2 the values of $\gamma_{7}$ and $\gamma_{0}$ are chosen to generate the same steady growth rate as in the simulation of section $3.2(g=n=0.03)$. This still leaves open the precise choice of $\gamma_{7}$ and the range of plausible values is not obvious. ${ }^{19} \mathrm{~A}$ large value of $\gamma_{7}$ implies that accumulation will depend inversely on utilization (given $k$ ) which may not seem reasonable; a small value of $\gamma_{7}$, on the other hand, makes the equilibrium solution for the employment rate very sensitive to variations in other parameters and exogenous variables. Fortunately, the value of $\gamma_{7}$ is of little importance for the qualitative results. Since the steady-growth values of $u$, $\alpha$ and $\beta$ are determined independently of the accumulation function by (24), (25), (9) and (27), the value of $\gamma_{7}$ does not change the equilibrium values of $u, \alpha$ and $\beta$, as long as $\gamma_{0}$ is set to produce the same steady state growth rate (in our case, 0.03 ); nor does the choice of $\gamma_{7}$ affect the signs of the partial derivatives of $u$ and $e$ with respect to financial changes. The only change lies in the magnitude of the partial derivatives of the employment rate with respect to financial parameters: when $\gamma_{7}$ changes by a factor $s$, the partial derivatives change by a factor $1 / s$.

Tables 4 and 5 present results for $\gamma_{7}=0.5$. As indicated by Table 4 , the model is stockflow inelastic. A decline in the retention rate and the share of investment financed by equity issues have expansionary effects on utilization and employment rates, as in 4.I, and the quantitative difference in the effects of a financial change between the cases with exogenous and endogenous stock-flows is very small. Stock-flow ratios, moreover, exhibit only moderate variations in response to substantial changes in $s_{f}, x$ and $r$ (Table 5), and the results are robust with respect to variations in the values of the consumption parameters, $c_{1}$ and $c_{2}$.

I9 Since employment and utilization move together in the short run but not necessarily in the long run, a dynamic specification with lagged employment effects (and small short-run but large long-run effects of changes in employment) could be used to resolve this problem. 
Thus, the financial changes commonly associated with financialization are expansionary in these simulations: they tend to raise both utilization and employment rates in this labor constrained Kaleckian economies.

Table 4: Labor Constrained Kaleckian Economy

\begin{tabular}{lcccc}
\hline \multicolumn{1}{c}{ Regimes } & \multicolumn{2}{c}{ Utilization } & \multicolumn{2}{c}{ Employment } \\
& $\boldsymbol{\alpha}$ and $\boldsymbol{\beta}$ & $\alpha$ and $\boldsymbol{\beta}$ & $\boldsymbol{\alpha}$ and $\boldsymbol{\beta}$ & $\boldsymbol{\alpha}$ and $\boldsymbol{\beta}$ \\
\hline The retention rate & -0.574 & -0.567 & -0.057 & -0.057 \\
\hline Equity issues & -0.510 & -0.488 & -0.051 & -0.049 \\
Real interest rate & 1.368 & 1.345 & -0.063 & -0.065 \\
Profit share & -1.428 & -1.410 & -0.143 & -0.141 \\
\hline Propensity to hold equity & - & 0.029 & - & 0.003 \\
\hline
\end{tabular}

Notes: The results are based on the system of (9), (24), (25), (27) and (4I) in section 4.2.

a. Numbers in the table show the partial derivatives of the utilization rate and the employment rate with respect to the parameters listed in the first column.

b. $\left(\gamma_{0}, \gamma_{1}, \gamma_{3}, \gamma_{7}\right)=(0.4847,0.05 ; 0.1,0.5),\left(s_{f}, \pi, x\right)=(0.75,0.33,0.05),\left(c_{1}, c_{2}\right)=(0.75,0.064)$, $\left(\lambda_{0}, \lambda_{1}, \lambda_{2}, \lambda_{3}\right)=(0.6,0.2,0.013,0.0001),(i, \hat{p}, n, d)=(0.03,0,0.03,0.1)$.

Table s: Effects of Changes in Financial Variables on Stock-flow Ratios in Labor Constrained Kaleckian Economy

\begin{tabular}{c|ccc|ccc|ccc}
\hline & \multicolumn{3}{|c|}{$\boldsymbol{s}_{f}$} & \multicolumn{3}{c|}{$\boldsymbol{x}$} & \multicolumn{3}{c}{$\boldsymbol{r}$} \\
& $\mathbf{0 . 5 5}$ & $\mathbf{0 . 7 5}$ & $\mathbf{0 . 9 5}$ & $-\mathbf{0 . 0 5}$ & $\mathbf{0 . 0 5}$ & $\mathbf{0 . 1 5}$ & $\mathbf{0 . 0 1}$ & $\mathbf{0 . 0 3}$ & $\mathbf{0 . 0 5}$ \\
\hline $\boldsymbol{\alpha}$ & 1.554 & 1.407 & 1.258 & 1.614 & 1.407 & 1.154 & 1.385 & 1.407 & 1.432 \\
$\boldsymbol{\beta}$ & 1.056 & 0.958 & 0.858 & 1.098 & 0.958 & 0.787 & 0.927 & 0.958 & 0.991 \\
\hline
\end{tabular}

Notes: $0.75\left(s_{f}\right), 0.05(x), 0.03(r)$ are the baseline values. For other baseline parameter values, see notes in Table 4.

\section{Robustness}

\section{I Heterogeneous Households}

Our models in sections 3-4 specified consumption and portfolio behaviour for an aggregate household sector. The results obtained by van Treeck (2007) may suggest that this restriction affects our results. 
Van Treeck (2007) distinguishes between workers and rentiers, assuming that only rentiers save and make portfolio decisions between equities and deposits. Using these alternative assumptions, equation (24) and (25) are replaced by:

$$
\begin{aligned}
\frac{C}{K} & =(1-\pi) u+\bar{c}_{1} y_{r}+c_{2} q \\
\frac{\beta}{\alpha+\beta} & =\left(1-\lambda_{0}\right)+\lambda_{1}(r+\hat{p})-\lambda_{2} r^{e}+\lambda_{3} y_{r} / q
\end{aligned}
$$

The first term in (42) - the wage bill divided by the value of the capital stock - equals workers' real consumption normalized by $K$. The sum of the second and third term represents rentiers' consumption which is determined by their distributed income, $y_{r}=\left[\left(1-s_{f}\right)(\pi u-r m)+i m\right]$, and their wealth, $q \cdot{ }^{20}$ Equation (43) is essentially the same as (25) but $y$ in (25) is replaced by $y_{r}$ since only rentiers hold financial assets in the current model.

Except for the consumption function, van Treeck uses specifications that are very similar to the Lavoie-Godley model (200I-2). ${ }^{21}$ As in Lavoie and Godley (200I-2), the investment function, using our notation, is given by:

$$
g=\gamma_{0}+\gamma_{1} u+\gamma_{4} q-\bar{\gamma}_{5} r m+\gamma_{6} c
$$

Equation (44) can be obtained by setting $\gamma_{2}=\gamma_{3}=0$ and $\gamma_{5}=\bar{\gamma}_{5} r$ in (2). The main departure from the original Lavoie-Godley investment function lies in different numerical values assigned to the Tobin's-q effect, $\gamma_{4}$. The implications of the particular set of the parameter values will be discussed below.

As in section 3.2, five equations, along with proper definitions of $q, m, c$ and $r^{e}$, determine the steady state values of $u, g, C / K, \alpha$ and $\beta$, and we can conduct comparative statics regarding the effects on these equilibrium values of changes in $s_{f}$ and $x$.

Using a framework that is essentially equivalent to (9), (27), (42)-(44), van Treeck's results indicate that the effects of a decrease in the retention rate $\left(s_{f}\right)$ and the share of investment financed by equity issues $(x)$ depend on parameter values and that, he suggests, the effects can be contractionary for plausible parameter constellations. This conclusion may seem surprising, given the similarity of the model to those analyzed by Lavoie and Godley (200I-02) and Skott and Ryoo (2008).

20 Following Godley and Lavoie (2007), van Treeck assumes that rentiers have access to credit to finance their consumption. The amount of credit is determined by the level of their net worth and disposable income. In addition, banks make profits (which are distributed to rentiers) since the loan rate of interest is determined by a markup on the deposit rate. It can be shown, however, that van Treeck's specification can be reduced to (42).

2I Following Hein (2007), van Treeck (2007) assumes that firms' markup is influenced by their dividend policy. Thus, in his simulations changes in $s_{f}$ are always combined with changes in $\pi$, and his results are not directly comparable to those with a constant profit share. Our simulations in this section leave out the assumed link between the retention rate and the markup and take the profit share as exogenous. 
Table 6 is constructed in the same way as Table $\mathrm{I}$, but using the specification in equations (42)-(44) and van Treeck's parameter values for the contractionary case. The signs of the partial derivatives of $u$ and $g$ with respect to $s_{f}, x$ and $r$ are all reversed as we move from the case with exogenous $\alpha$ and $\beta$ to that with endogenous ratios. In particular, a fall in either $s_{f}$ or $x$ leads to a decline in both $u$ and $g$ for endogenous ratios but an increase in both $u$ and $g$ for exogenous ratios. Thus, the van Treeck model for the contractionary case represents a stock-flow elastic system in which the endogenous adjustment of $\alpha$ and $\beta$ in response to a financial change is very large in magnitude. Table 7 illustrates these large responses of the stock-flow ratios; a change in the retention rate from 0.85 to 0.65 , for instance, raises the stock-flow ratios by more than a factor three.

Table 6: Kaleckian Dual-economy: van Treeck (2007)

\begin{tabular}{lcccc}
\hline \multicolumn{1}{c}{ Regimes } & \multicolumn{2}{c}{ Utilization } & \multicolumn{2}{c}{ Accumulation } \\
& $\begin{array}{l}\text { Exogenous } \\
\text { and } \boldsymbol{\beta}\end{array}$ & $\begin{array}{c}\text { Endogenous } \\
\boldsymbol{\alpha} \text { and } \boldsymbol{\beta}\end{array}$ & $\begin{array}{c}\text { Exogenous } \\
\text { Endogenous }\end{array}$ & $\begin{array}{c}\boldsymbol{\alpha} \text { and } \boldsymbol{\beta} \\
\boldsymbol{\alpha} \text { and } \boldsymbol{\beta}\end{array}$ \\
\hline The retention rate & -0.294 & 0.072 & -0.029 & 0.086 \\
\hline Equity issues & -0.407 & 0.006 & -0.095 & 0.036 \\
Real interest rate & 0.042 & -1.126 & -0.175 & -0.544 \\
Profit share & -0.473 & -0.893 & -0.047 & -0.180 \\
Propensity to hold equity & - & 0.094 & - & 0.030 \\
\hline
\end{tabular}

Notes: The results are based on the system of (9), (27) and (42)-(44). The parameter values are the same as or qualitatively equivalent to those in van Treeck (2007)'s contractionary case (Case I). See note b. below.

a. Numbers in the table show the partial derivatives of the utilization rate and the growth rate with respect to the parameters listed in the first column.

b. Parameter values: $\left(\gamma_{0}, \gamma_{1}, \gamma_{4}, \bar{\gamma}_{5}, \gamma_{6}\right)=(0.0225,0.075,0,0.5,0.5),\left(s_{f}, \pi, x\right)=(0.65,0.45,0.025)$, $\left(\bar{c}_{1}, c_{2}\right)=(0.4,0.01),\left(\lambda_{0}, \lambda_{1}, \lambda_{2}, \lambda_{3}\right)=(0.55,0.2,0.013,0.0001),(i, \hat{p})=(0.04,0)$.

Table 7: Effects of Changes in Financial Variables on Stock-flow Ratios: van Treeck (2007)

\begin{tabular}{c|ccc|ccc|ccc}
\hline & \multicolumn{3}{|c|}{$\boldsymbol{s}_{f}$} & \multicolumn{3}{c|}{$\boldsymbol{x}$} & \multicolumn{3}{c}{$\boldsymbol{r}$} \\
& $\mathbf{0 . 4 5}$ & $\mathbf{0 . 6 5}$ & $\mathbf{0 . 8 5}$ & $-\mathbf{0 . 0 5}$ & $\mathbf{0 . 0 2 5}$ & $\mathbf{0 . 1 5}$ & $\mathbf{0 . 0 2}$ & $\mathbf{0 . 0 4}$ & $\mathbf{0 . 0 6}$ \\
\hline $\boldsymbol{\alpha}$ & 2.687 & 1.387 & 0.413 & 1.867 & 1.387 & 0.595 & 1.137 & 1.387 & 1.941 \\
$\boldsymbol{\beta}$ & 2.255 & 1.162 & 0.345 & 1.565 & 1.162 & 0.496 & 0.935 & 1.162 & 1.656 \\
\hline
\end{tabular}

Notes: $0.65\left(s_{f}\right), 0.025(x), 0.04(r)$ are the baseline values. For other baseline parameter values, see note b. in Table 6 . 
Table 8: Effects of Changes in the Value of Consumption Wealth Effect Parameter $\left(c_{2}\right)$ on Comparative Statics in van Treeck (2007)

(a) $\gamma_{4}=0.0, \bar{\gamma}_{5}=0.5, \gamma_{6}=0.5$

\begin{tabular}{rcccccccc}
\hline$c_{2}$ & .005 & .01 & .02 & .03 & .04 & .05 & .06 & .07 \\
\hline$\partial u / \partial s_{f}$ & + & + & - & - & - & - & - & - \\
$\partial g / \partial s_{f}$ & + & + & + & + & + & - & - & - \\
$\partial u / \partial x$ & + & + & - & - & - & - & - & - \\
$\partial u / \partial x$ & + & + & - & - & - & - & - & - \\
\hline
\end{tabular}

(b) $\gamma_{4}=0.0, \bar{\gamma}_{5}=0.2, \gamma_{6}=0.2$

\begin{tabular}{rcccccccc}
\hline$c_{2}$ & .005 & .01 & .02 & .03 & .04 & .05 & .06 & .07 \\
\hline$\partial u / \partial s_{f}$ & - & - & - & - & - & - & - & - \\
$\partial g / \partial s_{f}$ & + & - & - & - & - & - & - & - \\
$\partial u / \partial x$ & - & - & - & - & - & - & - & - \\
$\partial u / \partial x$ & + & - & - & - & - & - & - & - \\
\hline
\end{tabular}

(c) $\gamma_{4}=0.01, \bar{\gamma}_{5}=0.5, \gamma_{6}=0.5$

\begin{tabular}{rcccccccc}
\hline$c_{2}$ & .005 & .01 & .02 & .03 & .04 & .05 & .06 & .07 \\
\hline$\partial u / \partial s_{f}$ & - & - & - & - & - & - & - & - \\
$\partial g / \partial s_{f}$ & + & + & + & - & - & - & - & - \\
$\partial u / \partial x$ & - & - & - & - & - & - & - & - \\
$\partial u / \partial x$ & - & - & - & - & - & - & - & - \\
\hline
\end{tabular}

Notes: For parameter values except those of $c_{2}, \gamma_{4}, \bar{\gamma}_{5}$ and $\gamma_{6}$, see note b. in Table 6 . In the case of exogenous $\alpha$ and $\beta$, for all listed values of $c_{2}$, the four key partial derivatives have all negative signs.

The choice of parameter values explain these results. The wealth parameter in the consumption function, first, is set at $c_{2}=0.01$, much lower than the Lavoie-Godley value of 0.064 . Table 8a illustrates the importance of this low value of $c_{2}$ for the results: higher values of $c_{2}$ generate comparative static results that conform to those with an exogenous stock-flow ratio (for all listed values of $c_{2}$, the partial derivatives of $u$ and $g$ with respect to $s_{f}$ and $x$ are negative in the case with exogenous $\alpha$ and $\beta$ ). van Treeck suggests that in practice the wealth effect may be low, at least in some countries (van Treeck 2007: 22-25), but even if one were to 
accept a small wealth effect on consumption, the contractionary results still look questionable. They also depend heavily on the parameter values in the accumulation function.

The accumulation function is the same as the one in Lavoie and Godley (200I-2) but whereas Lavoie and Godley use $\gamma_{4}=0.02$, van Treeck assumes that Tobin's $q$ has no effect on investment, that is, $\gamma_{4}=0$. He refers to some econometric studies which suggest that Tobin's q effect is insignificant (van Treeck 2007: 2I-22) but his assumption that $\gamma_{4}=0$, combined with other features of the model, implies more than what those econometric studies may suggest: essentially, it makes utilization depend negatively on Tobin's q. To see this, note first that the parameter values in households' portfolio equations make the $m / q$ ratio very insensitive to changes in firms' financial decisions; that is, we have $m=\mu q$ for some constant factor $\mu$. This proportionality implies that after controlling for the effects of utilization $(u)$ and retained earnings $(c)$, the effect of $q$ on investment can be written: $\gamma_{4}-\bar{\gamma}_{5} r \mu$, and given the parameter values for his contractionary case, the approximate magnitude of $\gamma_{4}-\bar{\gamma}_{5} r \mu$ is $-0.01 .^{22}$ In addition, an increase in $q$, leading to an increase in $m$, has an indirect negative effect on investment since it reduces retained earnings, $c$. The magnitude of this effect $\left(-S_{f} \gamma_{6} r \mu\right)$ is around $-0.007 .{ }^{23}$ Thus, the van Treeck simulations combine the absence of a Tobin's-q effect with a strong negative debt effect, ${ }^{24}$ and as a result firms' accumulation depends negatively on their market value $(q)$, keeping $u$ constant. An inverse relation between Tobin's $q$ and the rate of utilization now follows if the value of $c_{2}$ is set so low that the positive effect of a rise in $q$ on consumption does not offset the negative overall effect of $q$ on investment. It is hard to believe that this feature is empirically plausible.

Tables $8 \mathrm{~b}$ and $8 \mathrm{c}$ illustrate the importance of the investment parameters for the contractionary cases. Table $8 \mathrm{~b}$ considers the effects of changes in $c_{2}$ on the comparative statics for different values of $\bar{\gamma}_{5}$ and $\gamma_{6}$. When both are set to 0.2 , the overall effect of a rise in $q$ on accumulation controlling for utilization remains negative but modest, and in this case $c_{2}=0.01$ is sufficient to make the system stock-flow inelastic with expansionary effects of a reduction in $s_{f}$ and $x$. Table 8c uses the van Treeck values $\bar{\gamma}_{5}=\gamma_{6}=0.5$ but allows for a small positive q-effect on investment, $\gamma_{4}=0.01$ (only half the value used by Lavoie and Godley). In this case, for all listed values of $c_{2}$, three of the key partial derivatives $-\partial u / \partial s_{f}, \partial u / \partial x$ and $\partial g / \partial x$ - are all negative as in the case with exogenous stock-flow ratios. $c_{2} \geq 0.03$ produces stock-flow inelastic results by eliminating the cases where the other key partial derivative $\partial g / \partial s_{f}$ is positive.

22 In van Treeck's experiments, $\gamma_{4}=0, \bar{\gamma}_{5}=0.5, r=0.05$ and $\mu \approx 0.4$ which gives us $\gamma_{4}-\bar{\gamma}_{5} r \mu \approx-0.01$.

23 In van Treeck's experiments, $s_{f}=0.65, \gamma_{6}=0.5, r=0.05$ and $\mu \approx 0.4$ which gives us $-s_{f} \gamma_{6} r \mu \approx-0.007$.

24 The original Lavoie-Godley model (200I-2) also has this strong negative debt effect due to the assumption of high values for $\bar{\gamma}_{5}$ and $\gamma_{6}$ so that an increase in interest payment by one dollar reduces the level of investment by almost one dollar holding $u$ and $q$. However, in their model, the strong negative debt effect is balanced by a strong positive Tobin's q effect $\left(\gamma_{4}=0.02\right)$ leading to a moderately positive overall effect of an increase in $q$ on $g$, keeping $u$ constant. 
Overall, our reading of the empirical evidence suggests that implausible parameter constellations are needed in order to produce stock-flow elasticity and contractionary outcomes.

\subsection{Employment and the NAIRU}

The analysis of a labor-constrained economy in section 4.2 implies that demand shifts can produce permanent employment effects. This result clearly goes against standard theories of a structurally determined NAIRU, but despite its widespread acceptance in the profession today, NAIRU theory is both theoretically and empirically weak. There are many reasons to expect a role for aggregate demand, also in the medium and long term. Suspending our disagreements with NAIRU theory, however, a straightforward modification of the accumulation function makes the long-run employment rate invariant with respect to shifts in financial practices.

Assume that, given the structural characteristics of the economy, there is a unique value of the employment rate $e^{*}$ for which the competing claims of workers and firms become mutually consistent, employment rates above $e^{*}$ leading to high claims and ever-increasing inflation. Fiscal and/or monetary policy intervention provides one way of bringing the average employment rate into equality with $e^{*}$. Even without formal Taylor rules, policy makers can be expected to introduce contractionary measures if inflation is high and increasing and expansionary measures if there is high unemployment and low and decreasing inflation. This avenue is not open to us since, quite deliberately, our models focus on a pure capitalist economy without public sector, and »monetary policy « has been confined to the setting of a real rate of interest. But the same argument that underlies the ever-increasing inflation rate - the persistent and unresolved conflict over income distribution - may also manifest itself directly in the accumulation decisions.

If workers' real wage aspirations are persistently frustrated by price increases that exceed their expectations then there would seem to be only two possibilities: either workers will come to see their aspirations as unrealistic and will gradually reduce these aspirations or, alternatively, frustration with the distributional outcome will spill over into a heightened level of general worker militancy. The first possibility - aspirational hysteresis - negates our current assumption of a structurally determined NAIRU (Skott 1991, 1999 and 2005); the second possibility strongly suggests that there will be cumulative shifts in the accumulation function. As workers' militancy increases, the business climate and animal spirits progressively deteriorate. Algebraically, the same factors that may generate a unique NAIRU also suggest that the labor-constrained version of the accumulation be specified as

25 See Flaschel and Skott (2006) for a Steindlian model with dynamic adjustments in both the markup and the accumulation function.

26 They also introduce a flat segment in the otherwise increasing relation between employment and the wage-share aspiration. This flat segment, however, does not seem to play an important role for their results. 


$$
\begin{aligned}
& g=\gamma+\gamma_{1} u+\gamma_{2} \pi-\gamma_{3} r+\gamma_{4} q-\gamma_{5} m+\gamma_{6} c \\
& \dot{\gamma}=h\left(e^{*}-e\right) ; \quad h^{\prime}>0
\end{aligned}
$$

With this specification it is readily seen that in steady growth we must have $e=e^{*}$, and the changes in financial behavior that we have analyzed in sections 3-4 can have no long-run employment effects. ${ }^{25}$

It may be noted that in some ways the analysis in Godley and Lavoie (2007) runs along these lines. Their economy, first, is labor constrained, the rate of inflation is determined by a competing-claims argument, and real-wage aspirations are linked to employment. There is no aspirational hysteresis, but expected price inflation does not affect the growth in money wages and their specification produces a traditional tradeoff between employment and inflation (given the profit share), rather than a $N A I R U .{ }^{26}$ The long-run growth rate in their model, second, is brought into line with an exogenously given natural rate of growth largely as a result of economy policy. These important differences in the structure of the models make it difficult to compare the results in section 4 with those obtained by Godley and Lavoie (2007) and Lavoie (2007), whose simulations use the Godley-Lavoie model. These difficulties are compounded by the fact that in the Godley and Lavoie model any change in the retention rate or the proportion of investment financed by new issues is accompanied by a change in the profit share; Lavoie's results for an increase in $x$, for instance, should be compared to a weighted average of our results for a decrease in $x$ and an increase in $\pi$.

\section{Conclusion}

The effects of some of the signal changes associated with financialization are almost invariably expansionary in the Kaleckian models considered in this paper. To be sure, parameter constellations can be found that give contractionary effects but our reading of the empirical evidence suggests that these constellations may not be plausible.

In addition to the direct effects of changes in retention rates, equity financing and household portfolio behavior, there may be indirect effects. The changes in $s_{f}$ and $x$ may, as suggested by Hein and van Treeck (2007), induce changes in the profit share, or the accumulation function may shift down (the parameter go may decline) as shareholder value becomes dominant, as suggested by, among others, Stockhammer (2004). It is not clear to us, however, that observed changes of this kind must be seen as causally related to the changes in financial practices. An increase in the markup (the profit share), for instance, may have as much to do with institutional changes in the labor market or the effects of international trade and capital mobility on workers' bargaining power as with a decrease in retention rates.

It could be argued that the developments in labor markets and international trade are linked to financialization. To some extent this may be true, but the existence of linkages between financial changes and developments in labor markets and international trade does not privilege "financialization" as the key to the whole nexus of transformations. In any case, 
even if one views financialization as the central element, detailed examinations are needed of the mechanisms through which economic performance may be affected. Our analysis in this paper contributes to the literature on these mechanisms.

The focus on Kaleckian models in this paper complements the Skott and Ryoo (2008) analysis, with its greater emphasis on (our preferred) Harrodian specifications. Our results suggest that in the labor-constrained case the two approaches lead to similar conclusions: on balance the direct effects of the observed changes in the financial behavior of firms and households are likely to have been expansionary.

\section{Appendix A: Construction of Table I}

This appendix describes the procedure used to construct Table I (the baseline Kaleckian dual economy case in section 3.2). A similar procedure is used for Tables 2 and 3 (by changing some of the parameter values, $s_{f}, x$ and $r$ for Table 2, and $c_{1}$ and $c_{2}$ for Table 3 ) and for Tables 4-8.

\section{Kaleckian Dual Economy with Endogenous $\alpha$ and $\beta$}

The model is given by the following system of equations:

$$
\begin{aligned}
& \frac{C}{K}=c_{1} y+c_{2} q \\
& \frac{\beta}{\alpha+\beta}=\left(1-\lambda_{0}\right)+\lambda_{1}(r+\hat{p})-\lambda_{2} r^{e}+\lambda_{3} y / q \\
& g=\gamma_{0}+\gamma_{1} u-\gamma_{3} r \\
& \frac{C}{K}=u\left[1-s_{f}(\pi-r \beta)-\beta g\right]-x(g+d) \\
& u=\frac{C}{K}+g+d
\end{aligned}
$$

where $y=\left[1-s_{f}(\pi-r \beta)+\hat{p} \beta\right] u, r^{e}=\frac{\left(1-s_{f}\right)(\pi-\beta r) u+\alpha u g-x(g+d)}{\alpha u}$ and $q=(\alpha+\beta) u$. (24) $-(25)$ are the same as in the main text. In our simulations, we include the rate of fixed capital depreciation $(d)$. As a result, (27) and (26) are slightly modified to (9a) and (27a). ${ }^{27}$ (24), (25), (26), (9a) and (27a) determine the steady-state values of $u, g, C / K, \alpha$ and $\beta$. The solutions for $q, m$ and $r^{e}$ are obtained from applying relevant definitions of those variables. The partial derivatives of the solutions for endogenous variables with respect to $s_{f}, x, r, \pi$, and $\lambda_{0}$ can be calculated.

The following parameter values are used to obtain the numerical results in Table I.

27 Depreciation is included to obtain a plausible set of steady state values of $u, g, q, m$, and $r^{e}$ but the qualitative results in this paper do not change if depreciation is excluded. 


$$
\begin{array}{ll}
-\quad & \left(\gamma_{0}, \gamma_{1}, \gamma_{3}\right)=(0.0088,0.05,0.1),\left(s_{f}, \pi, x\right)=(0.75,0.33,0.05) \\
& (i, \hat{p}, d)=(0.03,0,0.1) \\
-\quad & \left(c_{1}, c_{2}\right)=(0.75,0.064),\left(\lambda_{0}, \lambda_{1}, \lambda_{2}, \lambda_{3}\right)=(0.6,0.2,0.013,0.0001)
\end{array}
$$

These parameter values produce the following steady-state values of $u, g, q, m, \alpha$ and $\beta$.

$$
u^{*}=0.485 ; g^{*}=0.03 ; q^{*}=1.147 ; m^{*}=0.465 ; \alpha^{*}=1.407 ; \beta^{*}=0.958
$$

The partial derivatives of the solutions for $u$ and $g$ with respect to $s_{f}, x, r, \pi$, and $\lambda_{0}$ are evaluated at these steady state values. The obtained values were reported in the third and fifth columns of Table I.

\section{Kaleckian Dual Economy with Exogenous $\alpha$ and $\beta$}

Using $\alpha^{*}$ and $\beta^{*}$, we can transform the above endogenous $\alpha$ and $\beta$ system to the exogenous $\alpha$ and $\beta$ system by dropping the consumption and portfolio choice functions, (24) and (25).

$$
\begin{aligned}
& g=\gamma_{0}+\gamma_{1} u-\gamma_{3} r \\
& \frac{C}{K}=u\left[1-s_{f}\left(\pi-r \beta^{*}\right)-\beta^{*} g\right]-x(g+d) \\
& u=\frac{C}{K}+g+d \\
& q=\left(\alpha^{*}+\beta^{*}\right) u \\
& m=\beta^{*} u
\end{aligned}
$$

By construction, the above five equations must yield the same steady state values as in (Ar). Then, the partial derivatives of the solutions for $u$ and $g$ with respect to $s_{f}, x, r$ and $\pi$, again, are evaluated at the same steady state equilibrium. The second and forth columns of Table I report these values.

\section{Appendix B: An Endogenous Natural Rate and Non-linear Employment Effects}

This appendix outlines a more general specification of the model with a non-linear employment effect on $I / K$ and an endogenous natural growth rate.

Assume that

$$
\begin{aligned}
& \frac{I}{K}=\gamma_{0}+\gamma_{1} u+\gamma_{2} \pi-\gamma_{3} r+\gamma_{4} q-\gamma_{5} m+\gamma_{6} c-f(e) ; f^{\prime}>0 \\
& n=n(e) ; \quad n^{\prime}>0
\end{aligned}
$$

The condition for the product market equilibrium is:

$$
(1-\beta u-x)\left\{\gamma_{0}+\delta_{0}+\delta u-f(e)\right\}=s_{f}(\pi-\beta r) u
$$


(BI) has at most two solutions for $u$ in $(0,(1-x) / \beta)$ for any given $e$. Let us assume the existence of the solutions and denote the larger (and stable) solution as $u=u(\mathrm{e})$ where $u^{\prime}<0$ for $e>\bar{e}$.

In this case the steady growth condition becomes

$$
g(e) \equiv \gamma_{0}+\delta_{0}+\delta u(e)-f(e)=n(e)
$$

and the comparative statics will be given by

$$
\frac{\partial e}{\partial z}=\frac{\phi^{\prime}}{1-\delta \phi^{\prime} u^{\prime}} \cdot\left(\left.\frac{\partial g}{\partial z}\right|_{e \text { constant }}\right)
$$

where $\phi$ is the inverse of the function $f(e)+n(e)$ with $\phi^{\prime}>0, z \in\left\{\pi, s_{f}, x, r, \alpha, \beta\right\}$, and the expressions for $\left.\frac{\partial g}{\partial z}\right|_{\text {constant }}$ are given by (I8)-(23). The growth effect is given by

$$
\frac{\partial g}{\partial z}=n^{\prime}(e) \frac{\partial e}{\partial z}
$$

Substantively, the results are unchanged compared to the linear case with an exogenous natural rate. Parameter changes that are expansionary in the model with an exogenous value of $\mathrm{n}$ are also be expansionary when $n$ is increasing in $e$. The only difference is that when $n=n(e)$, an expansionary effect involves an increase in both the level of employment and the rate of growth.

\section{Appendix C: Existence of a Steady Growth Path with $g=n$}

The Keynesian stability condition is given by

$$
s_{f}(\pi-r \beta)+\beta(\delta u+g)-(1-x)\left(\delta-\gamma_{7} \mu k\right)>0
$$

Assuming that this condition is satisfied for all values of $u$ and $k$, there is at most one nonnegative equilibrium solution for $u$ and, as in section 3.I, a positive solution exists as long as $\gamma_{0}+\delta_{0}>0$. Let us denote the solution as $u^{*}=u^{*}(k)$. It can be shown that $u^{*} \in(0,(1-x) / \beta)$ for any $k$ and, given the Keynesian Stability condition, it is easy to check that

$$
u^{*^{\prime}}(k)=-\frac{(1-x-\beta u) \gamma_{7} \mu u}{s_{f}(\pi-r \beta)+\beta(\delta u+g)-(1-x)\left(\delta-\gamma_{7} \mu k\right)}<0
$$

and

$$
\lim _{k \rightarrow \infty} u^{*}(k)=0
$$

We also have solutions for $e$ and $g$ for any given $k$ :

$$
\begin{aligned}
e^{*}(k) & =\mu u^{*}(k) k \\
g^{*}\left(u^{*}, k\right) & =\gamma_{0}+\delta_{0}+\left(\delta-\gamma_{7} \mu k\right) u^{*}(k)=\frac{s_{f}(\pi-r \beta) u^{*}(k)}{1-x-\beta u^{*}(k)}
\end{aligned}
$$


The dynamic path of $k$ is determined by

$$
\hat{k}=\frac{s_{f}(\pi-r \beta) u^{*}(k)}{1-x-\beta u^{*}(k)}-n=\chi(k)
$$

We have

$$
\frac{d \hat{k}}{d k}=\frac{s_{f}(\pi-r \beta)(1-x) u^{*^{\prime}}(k)}{\left\{1-x-\beta u^{*}(k)\right\}^{2}}=\chi^{\prime}(k)<0
$$

and, using $\left(\mathrm{C}_{1}\right)-\left(\mathrm{C}_{2}\right)$,

$$
\lim _{k \rightarrow \infty} \chi(k)=-n<0
$$

It follows that $k$ will converge to $k^{*}=0$ if $\chi(0) \leq 0$ and to $k^{*}=\chi^{-1}(0)$ if $\chi(0)>0$. The growth rate, asymptotically, is given by

$$
g^{*}=\min \left\{n, \frac{s_{f}(\pi-r \beta) u^{*}(0)}{1-x-\beta u^{*}(0)}\right\}
$$

Thus, if $\chi(0)<0$ (that is, $\left.n>\frac{s_{f}(\pi-r \beta) u^{*}(0)}{1-x-\beta u^{*}(0)}\right)$, the system degenerates to the case without labor constraint.

\section{References}

Ando, A., Modigliani, F. (1963): The life cycle hypothesis of saving: Aggregate implications and tests, American Economic Review, 53, 55-84.

Auerbach, P., Skott, P. (1988): Concentration, competition and distribution, International Review of Applied Economics, 2, 42-6I.

Bhaduri, A., Marglin, S.A. (I990): Unemployment and the real wage: The economic basis for contesting political ideologies, Cambridge Journal of Economics, I4, 375-393.

Dos Santos, C.H., Zezza, G. (2007): A simplified, benchmark, stock-flow consistent Post-Keynesian growth model, Working Paper, No. 503, The Levy Institute.

Dutt, A.K. (1984): Stagnation, income distribution and monopoly power, Cambridge Journal of Economics, 8 (I), 25-40.

Dutt, A.K. (1992): Conflict inflation, distribution, cyclical accumulation and crises, European Journal of Political Economy, 8, 579-597.

Dutt, A.K. (1997): Equilibrium, path dependence and hysteresis in post-Keynesian models, in: Arestis, P., Palma, G., Sawyer, M. (eds.), Capital controversy, Post-Keynesian economics and the history of economic thought: Essays in honour of Geoff Harcourt, London: Routledge.

Dutt, A.K. (2006): Aggregate demand, aggregate supply and economic growth, International Review of Applied Economics, 20 (3), 319-336.

Eichner, A. (1976): The megacorp and oligopoly, Cambridge: Cambridge University Press. 
Epstein, G. A. (ed.) (2005): Financialization and the world economy, Northampton, MA: Elgar.

Flaschel, P., Skott, P. (2006): Steindlian models of growth and stagnation, Metroeconomica, $57(3), 303-338$.

Godley, W., Cripps, F. (1983): Macroeconomics, Oxford: Fontana and Oxford University Press.

Godley, W., Lavoie, M. (2007): Monetary economics: An integrated approach to credit, money, income, production and wealth, London/Basingstoke: Palgrave Macmillan.

Goodwin, R. (1967): Growth cycle, in: Feinstein, C. H. (ed.), Socialism, capitalism and economic growth. Essays presented to Maurice Dobb, Cambridge: Cambridge University Press.

Hein, E. (2007): Interest rate, debt, distribution and capital accumulation in a post-Kaleckian model, Metroeconomica, 57, 310-339.

Hein, E., van Treeck, T. (2007): ' Financialisation in Kaleckian/post-Kaleckian models of distribution and growth, Working Paper, No. 7/2007, Hans Boeckler Stiftung.

Krippner, G. (2005): The financialization of the American economy, Socio-Economic Review, 3, I73-208.

Kurz, H. (1986): Normal positions and capital utilization, Political Economy, 2 (I), 37-54.

Lavoie, M. (1995): The Kaleckian model of growth and distribution and its neo-Ricardian and neo-Marxian critiques, Cambridge Journal of Economics, 19, 789-818.

Lavoie, M. (1995a): Interest rates in post-Keynesian models of growth and distribution, Metroeconomica, 46(2), I46-I77.

Lavoie, M. (2007): Financialization issues in a post Keynesian stock-flow consistent model, mimeo.

Lavoie, M., Godley, W. (200I-2): Kaleckian models of growth in a coherent stock-flow monetary framework: A Kaldorian view Journal of Post Keynesian economics, 24 (2), 277-3II.

Lee, F. S. (1985): , Full cost‘ prices, classical price theory, and long period method analysis: A critical evaluation, Metroeconomica, 37 (2), 199-219.

Marglin, S., Bhaduri, A. (1990): Profit squeeze and Keynesian theory, in: Marglin, S., Schor, J. (eds.), The golden age of capitalism - reinterpreting the postwar experience, Oxford: Clarendon.

Ndikumana, L. (1999): Debt service, financing constraints, and fixed investment: Evidence from panel data, Journal of Post Keynesian Economics, 2I(3), 455-478.

Palley, T. (1996): Growth theory in a Keynesian mode: Some Keynesian foundations for new growth theory, Journal of Post Keynesian Economics, I9 (I), II3-I35.

Palley, T. (2007): Financialization: What it is and why it matters, Working Paper, No. 525, The Levy Economics Institute.

Robinson, J. (1962): Essays in the theory of economic growth, London/Basingstoke: Macmillan.

Rowthorn, B. (198I): Demand, real wages and economic growth, Thames Papers in Political Economy, Autumn.

Skott, P. (1981): On the 'Kaldorian saving function`, Kyklos, 34, 563-8I. 
Skott, P. (1988): Finance, accumulation and the choice of technique, Cambridge Journal of Economics, I2, 339-354.

Skott, P. (1989): Conflict and effective demand in economic growth, Cambridge: Cambridge University Press.

Skott, P. (I989a): Effective demand, class struggle and cyclical growth, International Economic Review, 30, 23I-247.

Skott, P. (I99I): Efficiency wages, mark-up pricing and effective demand, in: Michie, J. (ed.), The economics of restructuring and intervention, Aldershot: Edward Elgar.

Skott, P. (I999): Wage formation and the (non-) existence of the NAIRU, Economic Issues, March, 77-92.

Skott, P. (2005): Fairness as a source of hysteresis in employment and relative wages, Journal of Economic Behavior and Organization, 57, 305-33I.

Skott, P. (2008): Theoretical and empirical shortcomings of the Kaleckian investment function, University of Massachusetts Amherst, Department of Economics, Working Paper, No. 2008-II.

Skott, P., Ryoo, S. (2008): Macroeconomic implications of financialization, Cambridge Journal of Economics, forthcoming.

Stockhammer, E. (2004): Financialisation and the slowdown of accumulation, Cambridge Journal of Economics, 28, 719-74I.

Stockhammer, E. (2004a): The rise of unemployment in Europe, Cheltenham: Elgar.

Stockhammer, E. (2005-6): Shareholder value orientation and the investment-profit puzzle, Journal of Post Keynesian Economics, Winter 2005-6, 28 (2), I93-215.

Taylor, L. (1985): A stagnationist model of economic growth, Cambridge Journal of Economics, 9, 383-403.

Taylor, L. (199I): Income distribution, inflation, and growth: Lectures on structuralist macroeconomic theory, MIT Press.

Wood, A. (1975): A theory of profit, Cambridge: Cambridge University Press.

Van Treeck, T. (2007): A synthetic, stock-flow consistent macroeconomic model of financialization, mimeo. 